\title{
The effect of distribution processes on the isomeric composition of hexachlorocyclohexane in a contaminated riverine system
}

\author{
M. Berger ${ }^{1} \cdot$ D. Löffler ${ }^{2}$ T. Ternes ${ }^{2} \cdot$ P. Heininger ${ }^{2} \cdot$ M. Ricking ${ }^{3}$. \\ J. Schwarzbauer ${ }^{1}$
}

Received: 27 February 2015/Revised: 5 October 2015/Accepted: 11 January 2016/Published online: 25 January 2016

(C) Islamic Azad University (IAU) 2016

\begin{abstract}
Various factors influence the isomeric composition of hexachlorocyclohexanes which are released to the environment. Original compositions in technical mixtures may vary slightly, but higher shifts are observable for transfer processes, bioaccumulation and microbial transformation. Consequently, the isomeric composition in environmental samples is a superposition of these processes. In this study, isomeric distributions and concentrations of hexachlorocyclohexanes were analyzed in water, sediment, and soil samples of a riverine system known to be highly contaminated by hexachlorocyclohexanes. To assess desorption of hexachlorocyclohexanes from particulate matter to water, batch shaking and percolation experiments were conducted complementary. Analyzed samples exhibited total hexachlorocyclohexane concentrations of up to $2.8 \mu \mathrm{g} / \mathrm{g}$ in sediments and up to $21 \mu \mathrm{g} / \mathrm{L}$ in river water predominated by the $\alpha$-isomer. Downstream hexachlorocyclohexane pattern changed toward $\delta$-isomer domination, while overall hexachlorocyclohexane concentrations decreased. Desorption experiments supported the assumption of discrimination by
\end{abstract}

Electronic supplementary material The online version of this article (doi:10.1007/s13762-016-0940-4) contains supplementary material, which is available to authorized users.

J. Schwarzbauer

jan.schwarzbauer@emr.rwth-aachen.de

1 Institute of Geology and Geochemistry of Petroleum and Coal, RWTH Aachen University, Lochnerstr. 4-20, 52056 Aachen, Germany

2 Federal Institute of Hydrology (BfG), 56068 Koblenz, Germany

3 Department of Geosciences, Free University of Berlin, 12249 Berlin, Germany preferred association of the $\alpha$ - and $\beta$-isomers with particulate matter, showing elevated mobilization of $\gamma-, \delta$ - and $\varepsilon^{-}$ hexachlorocyclohexanes and lower mobilization of the $\alpha$ and $\beta$-isomers. Soil samples of a riparian wetland exhibited elevated concentrations of hexachlorocyclohexanes exceeding $200 \mu \mathrm{g} / \mathrm{g}$ and predominance of $\alpha$-hexachlorocyclohexanes in the top soil layer. Subjacent soil layers showed rapidly decreasing hexachlorocyclohexane concentrations and an isomeric shift toward the $\beta$-isomer. The assumed preferential mobilization of $\beta$-hexachlorocyclohexane was supported by desorption experiments. This study demonstrated firstly that transfer processes influence substantially hexachlorocyclohexane isomer distribution in the aquatic environment. Secondly, conditions of aging determine strength of association and remobilization potential of hexachlorocyclohexane residue down to an isomer-specific level.

Keywords Distribution processes .

Hexachlorocyclohexane · Isomer-specific · Lindane ·

Persistent organic pollutant

\section{Introduction}

Hexachlorocyclohexanes (HCHs) represent a group of persistent organic pollutants (POP) consisting of the eight isomers of 1,2,3,4,5,6-hexachlorocyclohexane. Five of these isomers (see Figure S1, supplement material) - $\alpha$ $\mathrm{HCH}, \beta-\mathrm{HCH}, \gamma-\mathrm{HCH}, \delta-\mathrm{HCH}$ and $\varepsilon-\mathrm{HCH}-$ are of high environmental relevance according to the Stockholm Convention Annex A. HCHs have been used for decades as pesticides. Although only $\gamma-\mathrm{HCH}$ exhibits insecticidal properties, isomeric mixtures as yielded by technical synthesis were applied dominantly in the initial time period 
after the Second World War. Later on after 1950, purified $\gamma-\mathrm{HCH}$ (trade name: Lindane) was produced and applied until its termination of production in the majority of countries [e.g., in West Germany (1984) and in East Germany 1989]. Currently, it is still used in some Asian and African countries, e.g., India (Ali et al. 2014; Sharma et al. 2014).

Technical synthesis of $\mathrm{HCH}$ by chlorination of benzene using UV radiation yields a mixture (technical $\mathrm{HCH}$ ) of five stereoisomers with a typical composition of 60-70\% $\alpha-\mathrm{HCH}, 5-12 \% \quad \beta-\mathrm{HCH}, 10-12 \% \gamma-\mathrm{HCH}, 6-10 \% \quad \delta-$ $\mathrm{HCH}$ and 3-4 \% ع-HCH (Willett et al. 1998; Walker et al. 1999). In-depth examinations of structural properties of $\mathrm{HCH}$ are described by Li et al. (2011b). Different chemical and physical properties such as the environmentally relevant partition coefficient $K_{\mathrm{OW}}$ and water solubility $\mathrm{S}_{\mathrm{WL}}$ are caused by the stereochemical orientation of the chlorine atoms around the cyclohexane ring (see Table 1). While $\alpha$ $\mathrm{HCH}$ is much more soluble in water than the $\beta$ - and $\gamma$ isomers, this difference is not visible in the corresponding $K_{\mathrm{OW}}$ value. Higher variation is observable for the Henry's law constants with a significant lower value for the $\beta$-isomer. The environmental fate of each $\mathrm{HCH}$ isomer is influenced by these differences in the partition coefficients and solubility.

$\mathrm{HCH}$ are of high environmental relevance due to their high persistence, their tendency for bioaccumulation and their (eco-)toxicological effects (Bhatt et al. 2009; OliveroVerbel et al. 2011; Stockholm Convention on POPs). Certain isomers $(\alpha-\mathrm{HCH}$ and $\gamma-\mathrm{HCH})$ are known for their global, air-bound migration (Wania and Mackay 1996), whereas other isomers $(\beta-\mathrm{HCH}$ but also $\alpha-\mathrm{HCH})$ tend to bioaccumulate due to their lipophilic character (Willett et al. 1998; Kumar et al. 2006). Some isomers exhibit elevated toxicity $(\gamma-\mathrm{HCH})$ in aquatic environments (Oliveira and Paumgartten 1997) and even carcinogenic potential (Zou and Matsumura 2003). These diverse patterns of behavior are caused by slightly deviating physical-chemical properties, and therefore, an isomer-specific observation of HCHs in the environment is an important issue.

Numerous studies were performed on the occurrence of $\mathrm{HCH}$ in various environmental compartments such as air (e.g., Karlsson et al. 2000; Ding et al. 2007), soil (e.g., Manz et al. 2001; Schwartz et al. 2006), sediment (e.g., Heim et al. 2005; Ricking and Schwarzbauer 2008; Li et al. 2011a), water (e.g., Heemken et al. 2000), plants (e.g., Abhilash et al. 2008) and animals (e.g., Marth et al. 1997; Willett et al. 1998). Most of these studies focused either on selected isomers or on reported cumulated concentrations of all $\mathrm{HCH}$ isomers. Individual quantitative data for all environmentally relevant isomers have been published to a minor extent only. In some studies, specific values were reported only for selected main isomers (e.g., Gandrass and Zoll 1996; Marth et al. 1997; Heemken et al. 2000; Franke et al. 2005), whereas other studies solely reported cumulative values of HCHs (e.g., Wilken et al. 1994).

However, it is known that isomeric patterns of $\mathrm{HCH}$ deviate between but also within environmental compartments (e.g., Manz et al. 2001; Heinisch et al. 2005; Abhilash et al. 2008). The variation in isomer patterns is related to different environmental processes. On the one hand, transfer and transport processes can be responsible for isomer discrimination. Several studies reported $\mathrm{HCH}$ patterns dominated by $\alpha-\mathrm{HCH}$ or $\beta-\mathrm{HCH}$ in sediment and soil, whereas $\alpha-\mathrm{HCH}$ and $\gamma-\mathrm{HCH}$ constitute the major isomers found in airborne particulate matter (e.g., Bhatt et al. 2009). These distribution trends are illustrated by $\mathrm{HCH}$ patterns detected in various environmental compartments at Lake Baikal (Iwata et al. 1995).

On the other hand, biotic transformation by bacteria discriminates $\mathrm{HCH}$ isomers by preferred transformation of certain isomers. Various studies on $\mathrm{HCH}$ transformation by bacteria showed $\beta-\mathrm{HCH}$ to be more resistant to degradation under aerobic conditions as compared to the other isomers (Bhatt et al. 2009).

Further on, the comparatively small concentrations of $\gamma$ $\mathrm{HCH}$ in terrestrial and freshwater environmental compartments are due to its fast transformation, isomerization (Bachmann et al. 1988; Wu et al. 1997) and its higher tendency to evaporate, respectively. Emissions from industrial waste derived from purification processes of raw $\mathrm{HCH}$ mixtures also have a very low $\gamma-\mathrm{HCH}$ content. Further on, due to its relatively short half-life compared to the other isomers, high concentrations of $\gamma-\mathrm{HCH}$ within $\mathrm{HCH}$
Table 1 Physical-chemical properties of the most environmental prevalent $\mathrm{HCH}$ isomers as described by Xiao et al. (2004)

\begin{tabular}{llcllll}
\hline & $S_{\mathrm{WL}}\left(\mathrm{mol} / \mathrm{m}^{3}\right)$ & $S_{\mathrm{OL}}\left(\mathrm{mol} / \mathrm{m}^{3}\right)$ & $\log K_{\mathrm{OW}}$ & $\log K_{\mathrm{OA}}$ & $H\left(\mathrm{~Pa} \mathrm{~m}{ }^{3} / \mathrm{mol}\right)$ & $P_{\mathrm{L}}(\mathrm{Pa})$ \\
\hline$\alpha-\mathrm{HCH}$ & 1.44 & 2870 & 3.94 & 7.46 & 0.735 & 0.245 \\
$\beta-\mathrm{HCH}$ & 0.333 & 11,800 & 3.91 & 8.74 & 0.037 & 0.0529 \\
$\gamma-\mathrm{HCH}$ & 0.247 & 1680 & 3.83 & 7.74 & 0.306 & 0.0757 \\
\hline
\end{tabular}

Data sets for $\delta$ - and $\varepsilon$-HCHs were not available for the author

$S_{\mathrm{WL}}, S_{\mathrm{OL}}$ and $P_{\mathrm{L}}$ refer to liquid state

$S_{W L}$ water solubility, $S_{O L}$ octanol solubility, $K_{O W}$ octanol/water partition coefficient, $K_{O A}$ octanol/air partition coefficient, $H$ Henry's law constant (air-water), $P_{L}$ vapor pressure 
patterns detected in natural samples indicate recent emission but exclude historical contamination (Ding et al. 2007). Regarding the occurrence of $\gamma-\mathrm{HCH}$, it has been suggested that Lindane may have been used preferentially in urban areas, while technical $\mathrm{HCH}$ was applied almost exclusively as an insecticide in agriculture (Venier and Hites 2014).

Various studies have been performed on metabolization (Macrae et al. 1967; Willett et al. 1998; Rodriguez-Garrido et al. 2004; Li et al. 2011b) and isomerization (Huhnerfuss et al. 1992; Wu et al. 1997; Phillips et al. 2005) of $\mathrm{HCH}$ isomers under different environmental conditions (redox environment, biotic/abiotic). Slightly different biotic transformations under aerobic and anaerobic conditions were proposed involving stepwise dechlorination to less chlorinated derivatives such as pentachlorocylohexene (e.g., Bachmann et al. 1988; Rodriguez-Garrido et al. 2004; Phillips et al. 2005; Ricking and Schwarzbauer 2008; Bhatt et al. 2009; Li et al. 2011b). Hydrolysis was reported as the dominant abiotic degradation pathway for $\mathrm{HCHs}$ (Bhatt et al. 2009).

In summary, various factors are influencing the isomeric composition of $\mathrm{HCHs}$ released to the environment. The original composition in technical mixtures may vary slightly, but higher shifts are observable for transfer processes, bioaccumulation and microbial transformation. Consequently, the isomeric composition in environmental samples is a superposition of these processes.

This study is a systematic analysis of the effect of environmental distribution processes on $\mathrm{HCH}$ composition in the aquatic environment. To achieve this objective, several environmental samples were taken from the riverine system of the Spittelwasser creek downstream of the former industrial area of Bitterfeld-Wolfen (Germany) in October 2012. Sediments, wetland soils, and surface water of this highly contaminated aquatic ecosystem were analyzed with respect to their isomer-specific $\mathrm{HCH}$ contamination. The water body, sediments, and wetlands of the Spittelwasser creek and the Mulde River system at Bitterfeld-Wolfen are well known for their high $\mathrm{HCH}$ pollution (Franke et al. 2005; Schwartz et al. 2006). At two chemical plants of the chemical-industrial complex Elektrochemisches Kombinat Bitterfeld upstream of the Spittelwasser creek Lindane was produced on an industrial scale from 1951 to 1982 at the times of the GDR (East Germany). Waste material from Lindane purification by recrystallization was dumped in former opencast pits creating a highly complex multipoint, almost diffuse source situation in this region. Until now, after 25 years of ceased production, high concentrations of $\mathrm{HCH}$ can be found in environmental compartments downstream of the industrial complex (e.g., Schwartz et al. 2006; Kolarikova et al. 2013). Being a tributary river to the Elbe River, the water quality of Germany's third largest river (Kolarikova et al. 2013), adjacent farmland as well as the North Sea (Huhnerfuss et al. 1997) has been affected by this contamination as well.

Complementary laboratory experiments were conducted to study the influence of isolated transfer and transport processes on $\mathrm{HCH}$ isomers and to simulate discrete natural processes such as flooding or remobilization of riverine sediments.

\section{Materials and methods}

\section{Sample material}

Samples were taken in October 2012 at various locations shown in Fig. 1 and Table 2 around Jeßnitz, north of Bitterfeld-Wolfen and the former industrial complexes. Three types of samples were taken to characterize the system: water samples, sediment samples, and soil samples from flooding areas. Two riverine systems are present in this area. The Schachtgraben canal is an approximately 3-km-
Fig. 1 Soil profile (left)-full scale indicates $30 \mathrm{~cm}$, continuous line marks surface border, and dotted lines mark border between visual distinguishable soil layers. Map of sampling area (right) - red dots indicate sampling point and associated sample number (see Table 2)

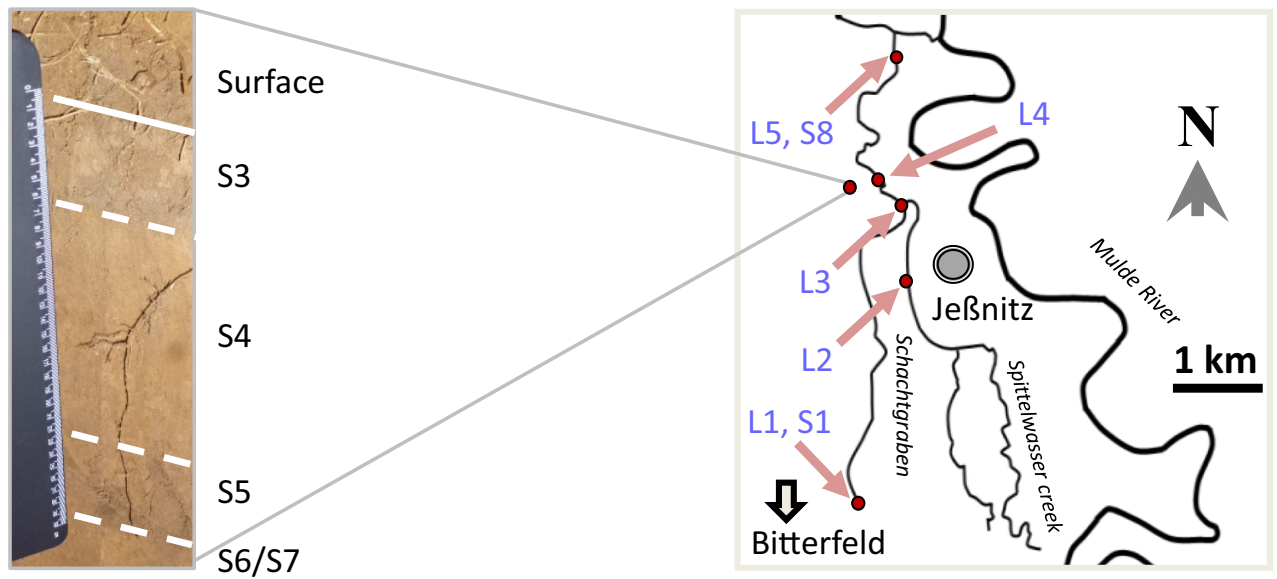


Table 2 Samples of the area Bitterfeld-Wolfen and their characterization by TOC and dry matter content

\begin{tabular}{lllll}
\hline & Sample no. & Description & TOC (\%) & Dry matter (\%) \\
\hline Particulate matter & S1 & Sediment-outlet Schachtgraben & 13.4 & 21.6 \\
& S2 & Soil-riparian wetland & 11.0 & 81.2 \\
& S3 & Soil-sampling depth 0-6 cm & 10.0 & 83.3 \\
& S4 & Soil-sampling depth 6-24 cm & 5.5 & 83.8 \\
& S5 & Soil-sampling depth 24-30 cm & 4.2 & 82.6 \\
& S6 & Soil-sampling depth 30-40 cm & 2.5 & 85.9 \\
S7 & Soil-sampling depth 40 cm & 2.3 & 85.8 \\
Water & S8 & Sediment-isolated pond & 4.1 & 41.2 \\
& L1 & Outlet Schachtgraben & & \\
L2 & Spittelwasser near Jeßnitz & & \\
L3 & Schachtgraben prior joining Spittelwasser & & \\
L4 & Spittelwasser near riparian wetland & & \\
L5 & Isolated pond & & \\
& W1 & Industrial HCH waste &
\end{tabular}

long canal originally set up to drain opencast pits and industrial wastewater. Nowadays, drainage water from dumps and further unknown sources within the area of former chemical plants are discharged (Schmidt et al. 2008). The Spittelwasser creek was subject to a similar fate in the past, and both recipients of the Mulde River and later the Elbe River are therefore still affected by the chemical industry. Water samples were taken at five different locations. The Schachtgraben canal was represented by samples L1 and L3 located at the beginning, respectively, the end of the canal. Water from this canal exhibited a red-brownish color. In particular at the beginning, a high quantity of suspended particulate matter as a result of elevated iron hydroxide precipitation was observed. This observation pointed to a high contribution of anaerobic mine drainage water in the Schachtgraben canal water. The Spittelwasser creek was characterized by sample L 2 prior the confluence with the Schachtgraben canal, sample L4 after inflow of the Schachtgraben canal, and sample L5, a pond fed by the Spittelwasser creek during flood events.

Two types of particulate matter were investigated in the Spittelwasser creek/Mulde River system: Sediment samples representing perpetual subaquatic particulate matter and soil samples only exposed sporadically to riverine water. The soils samples were included in this study, since during flood events remobilized sediment material can be deposited in large amounts on adjacent riparian wetlands. Sample S1 was a representative sediment from the Schachtgraben canal. At time of sampling, no fine-grained sediment was present in the Spittelwasser creek. Hence, sediment sample S8 was taken from a small, isolated pond next to the Spittelwasser creek, which is sporadically connected to the river. Thus, this sample can be characterized as a subaquatic deposit of the corresponding riverine sediments.
For batch desorption experiments, sample S2 was taken from the upper $20 \mathrm{~cm}$ of a test pit. To further investigate possible depth-dependent changes in $\mathrm{HCH}$ concentrations, a soil profile from a riparian wetland next to the Spittelwasser creek (samples S3-S7) was taken by sampling individual soil layers according to their color and texture shown in Fig. 1.

Soil and sediment samples were analyzed for TOC and dry matter content (see Table 2). Two representative samples were further characterized by their particle-size distribution (see supplement material Table S2).

Water samples L1-L5 were taken and stored in four $1 \mathrm{~L}$ glass flasks per sampling point at $4{ }^{\circ} \mathrm{C}$ in the dark. Soil profile samples S3-S7 were stored in $250 \mathrm{~mL}$ glass flasks with Teflon-lined screw caps. Sediment samples S1 and S8 and soil sample S2 were stored in sealable buckets. For comparison, a sample of matured industrial $\mathrm{HCH}$ waste $\mathrm{W} 1$ was provided by local authority. This waste was deposited for a prolonged period (minimum since ceased production of technical $\mathrm{HCH}$ in Bitterfeld-Wolfen over 25 years ago).

\section{Extraction and fractionation}

From each sampling point, $2 \mathrm{~L}$ water samples were processed in portions of $1 \mathrm{~L}$, respectively. Each $1 \mathrm{~L}$ aliquot was extracted using sequential liquid-liquid extraction (according to Franke et al. 1995) with $50 \mathrm{~mL}$ of $n$-pentane, $50 \mathrm{~mL}$ of DCM and $50 \mathrm{~mL}$ of DCM after acidification to pH 2 using conc. HCl. After each extraction step, the organic phase was separated via separating funnel. For quantification, $50 \mu \mathrm{L}$ of a surrogate standard mixture consisting of fluoroacetophenone $(7.2 \mathrm{ng} / \mu \mathrm{L})$, decafluorobenzophenone $(7.0 \mathrm{ng} / \mu \mathrm{L})$ and $\mathrm{d}_{34}$-hexadecane $(6.0 \mathrm{ng} /$ $\mu \mathrm{L})$ was then added to the first two extracts. To the third extract, $200 \mu \mathrm{L}$ of a different surrogate standard mixture 
consisting of fluoroacetophenone $(7.2 \mathrm{ng} / \mu \mathrm{L})$, decafluorobenzophenone $(7.0 \mathrm{ng} / \mu \mathrm{L})$ and difluorophenylacetic acid $(5.0 \mathrm{ng} / \mu \mathrm{L})$ was added. Then, the extracts were concentrated to approx. $5 \mathrm{~mL}$ by a rotary evaporator at ambient temperature and dried by filtration over anhydrous sodium sulfate. Thereafter, each two aliquots per sequentially processed extract was combined and concentrated to a final volume of ca. $50 \mu \mathrm{L}$ at ambient temperature.

Soil and sediment subsamples of $10 \mathrm{~g}$ were extracted by sequential ultrasonic agitation (according to Ricking and Schwarzbauer 2008) with $100 \mathrm{~mL}$ acetone and $100 \mathrm{~mL} n$ hexane. Each extraction step involved 15-min treatment by ultrasonication followed by a stirring period of $1 \mathrm{~h}$ and a second 15-min treatment by ultrasonication. Then, the samples were stirred overnight. The organic phase was separated from the dispersed solid material by centrifugation. The organic extracts were combined in a separating funnel, subsequently concentrated to a volume of approx. $5 \mathrm{~mL}$ by a rotary evaporator at ambient temperature and then dried by filtration over anhydrous sodium sulfate. After further concentration to approx. $1 \mathrm{~mL}$, activated copper powder was added and the sample was treated by ultrasonic agitation for $15 \mathrm{~min}$ and left overnight in a refrigerator.

Soil and sediment extracts were fractionated using glass microcolumns packed with approx. $2 \mathrm{~g}$ of activated silica gel (particle size $40 \mu \mathrm{m}$, dried overnight at $200{ }^{\circ} \mathrm{C}$ ). The fractionation was carried out by stepwise elution of $5 \mathrm{~mL}$ $n$-pentane, $8.5 \mathrm{~mL} n$-pentane/DCM 95:5 (v/v), $5 \mathrm{~mL} n$ pentane/DCM 90:10 (v/v), $5 \mathrm{~mL} n$-pentane/DCM 40:60 (v/ v), $5 \mathrm{~mL} \mathrm{DCM}$ and $5 \mathrm{~mL} \mathrm{MeOH}$, respectively. For quantification, $50 \mu \mathrm{L}$ of a surrogate standard mixture consisting of fluoroacetophenone $(7.2 \mathrm{ng} / \mu \mathrm{L})$, decafluorobenzophenone $(7.0 \mathrm{ng} / \mu \mathrm{L})$ and deuterohexadecane $(6.0 \mathrm{ng} / \mu \mathrm{L})$ was then added to fractions $1-5$. The fractions were then concentrated to $50 \mu \mathrm{L}$ at ambient temperature. $\mathrm{HCHs}$ were detected in fractions 3-5 of soil and sediment samples and extracts 1 and 2 of water samples.

\section{Batch desorption experiments}

Batch desorption experiments were conducted using samples S2, S8 and W1. In a first setup, $0.5 \mathrm{~L}$ Spree river water (Berlin) water was added to $250 \mathrm{~g}$ of wet sample material $(\mathrm{S} 2, \mathrm{~S} 8)$. The mixture was shaken with $7 \mathrm{rpm}$ in an endover-end-tumbler at $22{ }^{\circ} \mathrm{C}$. After $2 \mathrm{~h}, 24 \mathrm{~h}$ and 2 weeks, the samples were centrifuged $(10 \mathrm{~min}$ at $670 \times g)$ and the liquid phase was replaced.

In a second smaller setup considering the much higher concentrations of $\mathrm{HCH}$ pollutants in the waste sample $\mathrm{W} 1$, $40 \mathrm{~mL}$ Spree river water (Berlin) was added to $50 \mathrm{mg}$ (W1) and $40 \mathrm{~g}$ (wet S2) sample material, respectively, for the purpose of comparison to the first setup. The mixture was shaken with $7 \mathrm{rpm}$ in an overhead shaker. After $4 \mathrm{~h}$, $24 \mathrm{~h}, 1$ week and 2 weeks, the samples were centrifuged and the liquid phase was replaced. This procedure was performed four times, and corresponding water samples were combined due to difficulties in separating solid waste and water phase resulting in approx. $150 \mathrm{~mL}$ water samples per sampling point. All experiments were conducted in PE flasks. No sorption effects were observed.

Resulting water samples were filtered through $0.45 \mu \mathrm{m}$ filter (Macherey-Nagel MN GF-5, Germany) prior to analysis using the method described above. Results from the second-batch desorption experiment with soil sample S2 supported conclusions of first-batch desorption experiment using soil sample S2 and are therefore not described further.

\section{Percolation experiments}

Percolation experiments were conducted using samples S2 and S8. A column (stainless steel, $30 \mathrm{~cm} \times 10 \mathrm{~cm}$ i.d.) was packed with fine stainless steel gauze, $200 \mathrm{~g}$ aquarium gravel and $200 \mathrm{~g}$ of wet sample material (S2/S8) on top. Elution was done by gravity using $1 \mathrm{~L}$ Spree river water (Berlin) as eluent (roughly equivalent to $1 / 10$ th of average local annual precipitation). The percolation experiment with waste sample W1 was conducted using $884 \mathrm{mg}$ sample sealed with $100 \mathrm{~g}$ uncontaminated sand above $300 \mathrm{~g}$ aquarium gravel under the same conditions as sample S2 and S8. Portions of $100 \mathrm{~mL}$ eluate were taken and analyzed using the method described above.

\section{Gas chromatographic mass spectrometric analyses, GC/MS}

GC/MS analyses of soil profile samples S3-S7 were carried out on a double-focusing sector field mass spectrometer Finnigan MAT 95 (Finnigan MAT, USA) linked to a Modell 5890 Series II gas chromatograph (Hewlett Packard, USA) equipped with a $30 \mathrm{~m} \times 0.25 \mathrm{~mm}$ i.d. $\times 0.25 \mu \mathrm{m}$ ZB-1 fused silica capillary column (Phenomenex Inc., USA). One microliter of sample was injected as split/splitless injection with an injector temperature of $270{ }^{\circ} \mathrm{C}$ and a splitless time of $60 \mathrm{~s}$. The GC oven was programmed from hold for $3 \mathrm{~min}$ and then heated to $310{ }^{\circ} \mathrm{C}$ with a rate of $5{ }^{\circ} \mathrm{C} / \mathrm{min}$. Final isothermal time was $20 \mathrm{~min}$. The mass spectrometer was operated in electron impact ionization mode $\left(\mathrm{EI}^{+}, 70 \mathrm{eV}\right)$ in low-resolution scanning from 35 to $700 \mathrm{amu}$ at a rate of 1.0 scans/decade and an interscan time of $0.1 \mathrm{~s}$. The source temperature was held at $200{ }^{\circ} \mathrm{C}$. Helium carrier gas velocity was approximately $30 \mathrm{~cm} / \mathrm{s}$.

GC/MS analyses of water, sediment and non-profile soil samples were carried out on a Trace MS quadrupole mass 
spectrometer (ThermoQuest, Italy) linked to a Trace GC gas chromatograph (ThermoQuest, UK) with a $30 \mathrm{~m} \times 0.25 \mathrm{~mm}$ i.d. $\times 0.25 \mu \mathrm{m}$ ZB-XLB fused silica capillary column (Phenomenex Inc., USA) under the chromatographic conditions described above. The mass spectrometer was operated in electron impact ionization mode $\left(\mathrm{EI}^{+}, 70 \mathrm{eV}\right)$ in low-resolution scanning from 35 to $700 \mathrm{amu}$ at a scan rate of $1.5 \mathrm{scans} / \mathrm{s}$. The source temperature was held at $200{ }^{\circ} \mathrm{C}$. Helium carrier gas velocity was approximately $40 \mathrm{~cm} / \mathrm{s}$.

\section{Quantification}

$\mathrm{HCH}$ isomers were quantified by integration of the ion chromatograms 217 and $219 \mathrm{~m} / \mathrm{z}$. Retention order of $\mathrm{HCH}$ isomers were confirmed by a defined standard mixture of $\mathrm{HCH}$ isomers as following: $\alpha-\mathrm{HCH}, \beta-\mathrm{HCH}, \gamma-\mathrm{HCH}, \delta-\mathrm{HCH}, \varepsilon-\mathrm{HCH}$ (ZB-1-type column) and $\alpha$-HCH, $\gamma$-HCH, $\beta$-HCH, $\delta$-HCH, $\varepsilon$ $\mathrm{HCH}$ (ZB-XLB-type column). Quantification was carried out by an external four-point calibration using reference compounds (values for $\varepsilon-\mathrm{HCH}$ were derived from mean values of aforementioned $\mathrm{HCH}$ isomers). For correction of injection volume and sample volume inaccuracies, the results were corrected based on the surrogate standard $\mathrm{d}_{34}$ hexadecane. Reproducibility and analytical accuracy were tested by recovery experiments at least in triplicate (according to Dsikowitzky et al. 2002) to ensure analytical quality. Recovery rates for $\mathrm{HCH}$ in soil and sediment samples were determined by extraction of pre-extracted sediment samples spiked with $\mathrm{HCH}$ reference compounds and subsequent extraction and fractionation as described above (recovery rates and abs. STD: $\alpha-\mathrm{HCH} \quad(54 \% \pm 8), \quad \beta-\mathrm{HCH}$ $(66 \% \pm 10), \gamma-\mathrm{HCH}(60 \% \pm 10), \delta-\mathrm{HCH}(58 \% \pm 10), \varepsilon-$ $\mathrm{HCH}(59 \pm 10)$; values for $\varepsilon-\mathrm{HCH}$ derived from mean values of aforementioned $\mathrm{HCH}$ isomers). Recovery rates of $\mathrm{HCHs}$ in water samples were determined by extraction of water spiked with $\mathrm{HCH}$ reference compounds and subsequent extraction as described above (recovery rates and abs. STD: $\alpha-\mathrm{HCH}$ $(113 \% \pm 19), \beta-\mathrm{HCH} 111 \% \pm 26), \gamma-\mathrm{HCH}(119 \% \pm 17)$, $\delta$-HCH $(104 \% \pm 32), \varepsilon-H C H(112 \pm 20)$; values for $\varepsilon-\mathrm{HCH}$ derived from mean values of aforementioned $\mathrm{HCH}$ isomers).
Recovery rates were considered for quantitative data reported. All data of particulate matter are given on dry matter basis.

\section{Results and discussion}

\section{Sediment and water samples}

All quantitative results obtained for sediment and water samples are summarized in Table 3. Maximum values of total HCHs were approx. $2800 \mathrm{ng} / \mathrm{g}$ in sediments and approx. $21 \mu \mathrm{g} / \mathrm{L}$ in water.

Analyses of water samples revealed diverse isomeric patterns of HCHs throughout the examined area (see Fig. 2). At the outlet of the Schachtgraben canal L1, the runoff $\mathrm{HCH}$ pattern was strongly dominated by $\alpha-\mathrm{HCH}$ (87\%) accompanied by $10 \% \beta-\mathrm{HCH}$. Occurrence of other isomers was negligible. Besides changes in isomeric patterns, also changes in $\mathrm{HCH}$ concentrations were observed. Concentrations of dominant isomers, especially $\alpha-\mathrm{HCH}$, were exceptionally high in comparison with the other investigated water samples (see Table 3). Prior to joining the Spittelwasser creek at L3, the isomeric pattern shifted dramatically to a dominance of $\delta-\mathrm{HCH}(38 \%)$ followed by $\alpha$ - and $\beta$-HCHs both with approx. $24 \%$. This change in the isomer pattern was the result of decreasing concentrations of $\alpha-\mathrm{HCH}$ (by a factor of 100) and $\beta-\mathrm{HCH}$ (by a factor of 10), respectively. Complementary, the remaining three isomers $\gamma_{-}, \delta$ - and $\varepsilon$-HCHs exhibited no decrease in concentration over the canal's distance.

The Spittelwasser creek at L2 showed only a negligible contamination of $\mathrm{HCH}$ (see Table 3 ) with low concentrations of $\delta-\mathrm{HCH}$ and evenly distributed $\alpha$ - and $\beta$-HCHs. After the confluence of the Spittelwasser creek and Schachtgraben canal, only a minor shift in the $\mathrm{HCH}$ pattern toward a slight dominance of $\alpha-\mathrm{HCH}$ and even distributed $\beta$ - and $\delta$-HCH isomers was observed in the combined water body at L4. Between sample points L3 and L4, no change in $\mathrm{HCH}$ concentration occurred. The isomeric pattern in the pond water L5 exhibited a completely different distribution. Here, the pattern was predominated by $\beta-\mathrm{HCH}(62 \%)$ followed by $20 \%$ of $\alpha-\mathrm{HCH}$ and a significant percentage
Table $3 \mathrm{HCH}$ concentrations in sediment and water samples from Schachtgraben canal and Spittelwasser creek (concentration in $\mathrm{ng} / \mathrm{L}$ for water samples and $\mathrm{ng} / \mathrm{g}$ for sediment samples)

\begin{tabular}{lllllll}
\hline Sample no. & $\alpha-\mathrm{HCH}$ & $\beta-\mathrm{HCH}$ & $\gamma-\mathrm{HCH}$ & $\delta$-HCH & $\varepsilon-\mathrm{HCH}$ & $\Sigma-\mathrm{HCH}$ \\
\hline S1 & 210 & 130 & 4 & 13 & 11 & 368 \\
S8 & 1800 & 740 & 110 & 61 & 120 & 2831 \\
L1 & 18,000 & 2200 & 86 & 390 & 120 & 20,796 \\
L2 & 28 & 25 & n.d. & n.d. & n.d. & 53 \\
L3 & 130 & 130 & 24 & 200 & 45 & 529 \\
L4 & 190 & 140 & 16 & 140 & 40 & 526 \\
L5 & 48 & 150 & n.d. & 7 & 40 & 245 \\
\hline
\end{tabular}


Fig. $2 \mathrm{HCH}$ composition in water and sediment samples $(S 1$, $S 8, L 1-L 5$ and $W 1$ )

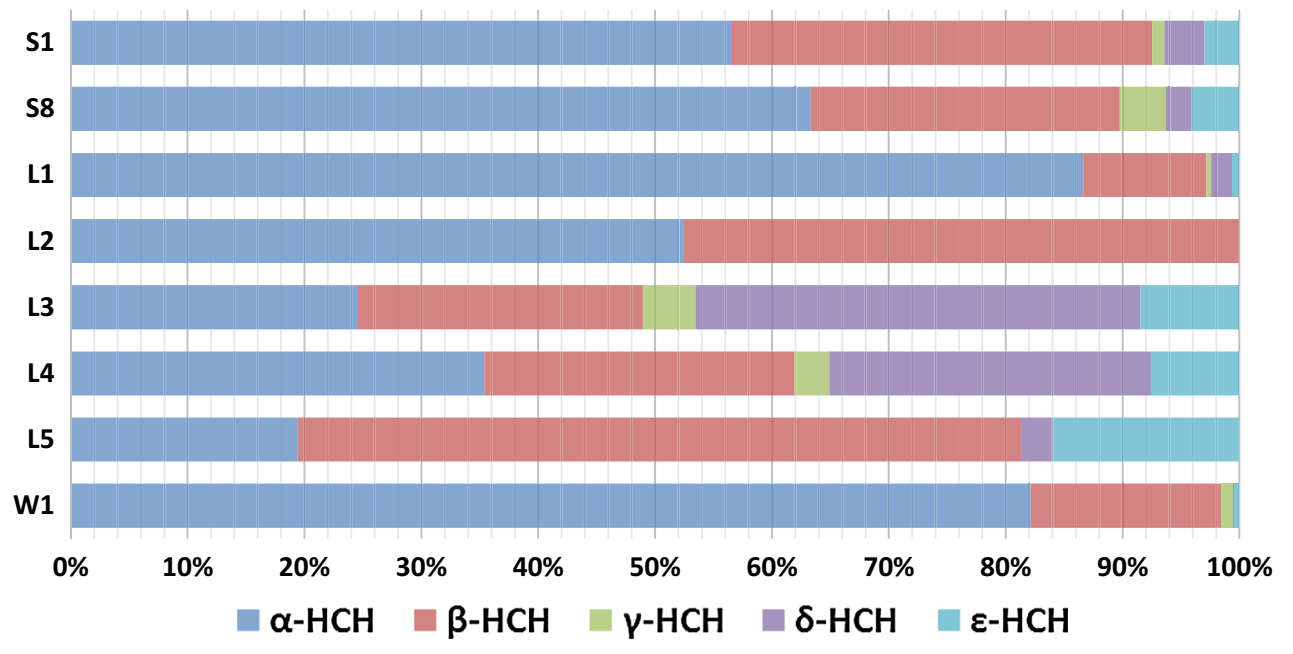

of $\varepsilon-\mathrm{HCH}$. It is worth mentioning that concentrations of $\beta$ and $\varepsilon$-HCHs were nearly constant in L3, L4 and L5, while there was a notable decrease in concentration of $\alpha$-, $\gamma$ - and $\delta$-HCHs between L3/L4 and L5. Former studies have shown that a roughly equal outflow rate can be assumed for both water bodies (Jacobs et al. 2013) represented in our study by sampling locations L2 and L3. However, the accordingly expected decrease in $\mathrm{HCH}$ concentration by factor of 0.5 at sampling point L4, representing the combined water bodies, was not observed. The lack of dilution effects might be attributed to an incomplete mixing of both bodies even $450 \mathrm{~m}$ after their confluence.

Analyses of sediment samples revealed only minor differences in $\mathrm{HCH}$ isomer patterns. Both sediments $\mathrm{S} 1$ and S8 were dominated by $\alpha-\mathrm{HCH}$ followed by $\beta-\mathrm{HCH}$ and minor percentages of the other isomers. Concentrations of total $\mathrm{HCH}$ increased by roughly a factor of 10 in $\mathrm{S} 8$ relative to $\mathrm{S} 1$.

Since the isomeric pattern at L1 (and to a lower extend at S1) was nearly identical to a pattern found in matured industrial HCH waste W1 (see Fig. 2), a close linkage can be assumed. A dramatic shift in the isomeric pattern was observed as the water body moves downstream. The clear decrease in $\alpha$ - and $\beta$-HCHs and simultaneously lack of decrease in the other remaining isomers between L1 and L3 points to a process primarily affecting the two dominant isomers of which $\alpha-\mathrm{HCH}$ is reduced in amounts ten times higher than $\beta-\mathrm{HCH}$. Interaction with particulate matter can be an explanation since the Schachtgraben canal exhibited elevated amounts of suspended matter in the form of iron hydroxides. Hence, adsorption or co-precipitation might lead to a favorable association of $\alpha$ - and $\beta$-isomers with the newly formed particulate matter.

As already mentioned, no fine-grained sediment was present in the Spittelwasser creek. Thus, the water-particle interaction is limited between L3 and L4 explaining the nearly unchanged isomeric pattern at L4. Contributions to a shift in the $\mathrm{HCH}$ pattern from contaminations of the Spittelwasser creek L2 prior to the joining of the Schachtgraben canal were negligible.

Although sediment of the stagnant water pond S8 exhibited the same pattern as the Schachtgraben canal sediment $\mathrm{S} 1$, the corresponding water sample L5 showed a completely different $\beta$-HCH-dominated isomeric pattern. This discrepancy is most likely caused by a steady runoff of fresh contamination from the Schachtgraben canal outlet and more extensive interaction with fluviatile sediment versus an almost equilibrium state between limnic sediment and corresponding water in the stagnant water pond.

To simulate the desorption processes, the transfer from particulate matter to surrounding water (mobilization), batch desorption experiments with material from sediment S8 were conducted. Results are shown in Table 4. Initially, only small amounts of $\alpha-, \beta-, \gamma-$ and $\delta$-HCHs, but a noticeable amount of $\varepsilon-\mathrm{HCH}$, were transferred to the liquid phase within the first $2 \mathrm{~h}$. After $24 \mathrm{~h}$, the amounts of mobilized $\alpha$ - and $\beta$-HCHs increased by a factor of 10 , while the mobilization of $\gamma-, \delta$ - and $\varepsilon$-HCHs remained constant. Lastly, after 2 weeks, further increase in mobilization of $\alpha-\mathrm{HCH}$ and to a lower extent of $\beta-\mathrm{HCH}$ and $\gamma-$ $\mathrm{HCH}$ was observed, while $\delta$ - and $\varepsilon-\mathrm{HCH}$ still remained constant. Net mobilization values were calculated by dividing the sum of individual $\mathrm{HCH}$ isomer content in all water aliquots by the sum of the content in the residual sediment and all water aliquots. Thus, a percentage value of mobilized $\mathrm{HCH}$ throughout the experiment was obtained. In contrast to the mobilization of $\alpha-\mathrm{HCH}$ and $\beta$ $\mathrm{HCH}$ (exhibiting comparatively low mobilization rates below $1 \%$ ), higher mobilization rates (between 1.8 and $6.1 \%$ ) for $\gamma-, \delta$ - and $\varepsilon$-HCHs were observed. Further on, a distinct dynamic behavior in mobilization of $\alpha-\mathrm{HCH}$ and $\beta$ $\mathrm{HCH}$ was visible, while $\gamma-, \delta$ - and $\varepsilon$-HCHs showed a 
Table 4 Results for batch desorption experiments from sediment sample S8 and soil sample S2

\begin{tabular}{|c|c|c|c|c|c|c|}
\hline \multirow[t]{2}{*}{ Sediment S8 } & \multicolumn{4}{|c|}{$\mathrm{HCH}$ in water phases of the batch experiment } & \multirow{2}{*}{$\begin{array}{l}\mathrm{HCH} \text { in sediment after the batch experiments } \\
\Sigma-\mathrm{HCH}_{\text {solid residue }}\end{array}$} & \multirow{2}{*}{$\begin{array}{l}\text { Mobilization }^{\mathrm{a}} \\
(\%)\end{array}$} \\
\hline & $2 \mathrm{~h}$ & $24 \mathrm{~h}$ & 2 weeks & $\Sigma$ - $\mathrm{HCH}_{\text {water }}$ & & \\
\hline$\alpha-\mathrm{HCH}$ & 26 & 360 & 1800 & 2200 & 270,000 & 0.8 \\
\hline$\beta-\mathrm{HCH}$ & 21 & 120 & 590 & 730 & 110,000 & 0.7 \\
\hline$\gamma-\mathrm{HCH}$ & 12 & 65 & 130 & 200 & 11,000 & 1.8 \\
\hline$\delta-\mathrm{HCH}$ & 90 & 57 & 82 & 230 & 9700 & 2.3 \\
\hline$\varepsilon-\mathrm{HCH}$ & 560 & 910 & 750 & 2200 & 34,000 & 6.1 \\
\hline$\Sigma-\mathrm{HCH}$ & 709 & 1512 & 3352 & 5560 & 434,700 & 1.3 \\
\hline \multirow[t]{2}{*}{ Soil S2 } & \multicolumn{4}{|c|}{$\mathrm{HCH}$ in water phases of the batch experiment } & $\mathrm{HCH}$ in soil after the batch experiments & Mobilization $^{\mathrm{a}}$ \\
\hline & $2 \mathrm{~h}$ & $24 \mathrm{~h}$ & 2 weeks & $\Sigma$ - $\mathrm{HCH}_{\text {water }}$ & $\Sigma-\mathrm{HCH}_{\text {soil residue }}$ & $(\%)$ \\
\hline$\alpha-\mathrm{HCH}$ & 2100 & 2800 & 2400 & 7300 & $1,200,000$ & 0.6 \\
\hline$\beta-\mathrm{HCH}$ & 25,000 & 22,000 & 34,000 & 82,000 & $2,000,000$ & 3.9 \\
\hline$\gamma-\mathrm{HCH}$ & 190 & 240 & 230 & 650 & 120,000 & 0.5 \\
\hline$\delta-\mathrm{HCH}$ & 180 & 200 & 370 & 760 & 83,000 & 0.9 \\
\hline$\varepsilon-\mathrm{HCH}$ & 470 & 530 & 780 & 1800 & 94,000 & 1.9 \\
\hline$\Sigma-\mathrm{HCH}$ & 27,940 & 25,770 & 37,780 & 92,510 & $3,497,000$ & 2.6 \\
\hline
\end{tabular}

Values of $\mathrm{HCH}$ contents are given in ng

${ }^{\text {a }}$ Mobilization $=\Sigma-\mathrm{HCH}_{\text {water }} /\left(\Sigma-\mathrm{HCH}_{\text {water }}+\Sigma-\mathrm{HCH}_{\text {solid residue }}\right) \times 100$

continuous mobilization rate. Opposing, a higher transfer rate from the water body to particulate matter for $\alpha-\mathrm{HCH}$ and $\beta-\mathrm{HCH}$ as compared to the other $\mathrm{HCH}$ isomers can be deduced from the batch desorption experiments. This supports well the observed behavior of $\alpha-\mathrm{HCH}$ and $\beta-\mathrm{HCH}$ between L1 and L3 in the Schachtgraben canal where these isomers were depleted to a higher extent from the water phase.

In water and sediment compartments, detected $\mathrm{HCH}$ patterns were subject to superimposition with other environmental processes. Physical processes such as evaporation are governed by physical properties of the individual $\mathrm{HCH}$ isomer (see Table 1). At the water-air-phase boundary, preferred evaporation of $\alpha-\mathrm{HCH}$ and $\gamma-\mathrm{HCH}$ over $\beta-\mathrm{HCH}$ is implied by their higher vapor pressure and Henry's law constant. It can be assumed that additional $\mathrm{HCH}$ transfer processes at water-sediment-phase boundary are very similar to the water-suspended matter interaction previously described by the conducted laboratory experiments. Complementary chemical processes include degradation and isomerization of HCHs. Both abiotic and biotic degradation pathways of $\mathrm{HCHs}$ were observed (Bhatt et al. 2009). Briefly, isomers of lower chlorinated cyclohexane derivatives such as pentachlorocyclohexene are formed by hydrolysis of $\mathrm{HCHs}$ ( $\mathrm{Li}$ et al. 2011b), the preferred abiotic degradation pathway. This hydrolysis is triggered by the potential of anti-elimination within the cyclic molecular system (Rodriguez-Garrido et al. 2004). Consequently, higher reactivity of $\alpha-\mathrm{HCH}$ and $\gamma-\mathrm{HCH}$ over $\beta-\mathrm{HCH}$ can be assumed. Biotic degradation of $\mathrm{HCHs}$ was observed under aerobic (aqueous-phase) and anaerobic (sediment-phase) conditions (Phillips et al. 2005), and numerous pathways were proposed ( $\mathrm{Li}$ et al. 2011b). General isomeric tendency to degradation is similar to abiotic reactions. Bioisomerization of $\gamma-\mathrm{HCH}$ to $\alpha-\mathrm{HCH}$ or $\beta-\mathrm{HCH}$ was described (Walker et al. 1999). In addition, under laboratory conditions, isomerization by photolysis was observed (Malaiyandi et al. 1982). However, only minor contributions from these other processes to the overall isomeric $\mathrm{HCH}$ distribution is assumed according to our results. Physical processes and degradation within the aqueous phase were not able to change drastically the isomeric $\mathrm{HCH}$ pattern in the creek between sample points L3 and $\mathrm{L} 4$, as well as in sediments between sample points $\mathrm{S} 1$ and S8.

\section{Industrial HCH waste}

Sample W1 (see Fig. 2) consisted of HCH waste derived from the purification process of technical $\mathrm{HCH}$ and was therefore $\gamma$-HCH-depleted. Small amounts of the $\gamma$-isomer were still present in this sample. Theoretically, isomerization to $\gamma-\mathrm{HCH}$ from other $\mathrm{HCH}$ isomers is possible as a single study reported (Deo et al. 1980), but the applied condition in that study (shaking in distilled water) is unlikely to be found in natural systems. Further reports suggest $\alpha-\mathrm{HCH}$ and/or $\beta-\mathrm{HCH}$ as preferred transformation products from bioisomerization of $\gamma-\mathrm{HCH}$ (Walker et al. 1999). 
Table 5 Results for batch desorption experiments from waste sample W1

\begin{tabular}{|c|c|c|c|c|c|c|c|}
\hline & \multicolumn{5}{|c|}{$\mathrm{HCH}$ in water phases of the batch experiment } & \multirow{2}{*}{$\begin{array}{l}\mathrm{HCH} \text { in waste after the batch experiments } \\
\Sigma-\mathrm{HCH}_{\text {waste residue }}\end{array}$} & \multirow{2}{*}{$\begin{array}{l}\text { Mobilization } \\
(\%)\end{array}$} \\
\hline & $4 \mathrm{~h}$ & $24 \mathrm{~h}$ & 1 week & 2 weeks & $\begin{array}{l}\Sigma- \\
\mathrm{HCH}_{\text {water }}\end{array}$ & & \\
\hline$\alpha-\mathrm{HCH}$ & 170 & 86 & 72 & 66 & 394 & 50,300 & 0.8 \\
\hline$\beta-\mathrm{HCH}$ & 17 & 9.6 & 6 & 5.6 & 38 & 15,300 & 0.2 \\
\hline$\gamma-\mathrm{HCH}$ & 170 & 88 & 53 & 31 & 342 & 1040 & 24.7 \\
\hline$\delta$ - $\mathrm{HCH}$ & 39 & 29 & 21 & 8 & 97 & 180 & 35.0 \\
\hline \multirow[t]{2}{*}{$\varepsilon-\mathrm{HCH}$} & 10 & 4.8 & 2.7 & 2.2 & 20 & 680 & 2.8 \\
\hline & 406 & 217 & 155 & 113 & 891 & 67,500 & 1.3 \\
\hline
\end{tabular}

Values of $\mathrm{HCH}$ content are given in $\mu \mathrm{g}$

${ }^{\text {a }}$ Mobilization $=\Sigma-\mathrm{HCH}_{\text {water }} /\left(\Sigma-\mathrm{HCH}_{\text {water }}+\Sigma-\mathrm{HCH}_{\text {waste residue }}\right) \times 100$

Thus, traces of residual $\gamma$-HCH illustrate an incomplete separation of $\mathrm{HCH}$ isomers by the $\mathrm{HCH}$ purification process.

To simulate initial mobilization by water contact, batch desorption experiments with sample W1 were performed and results are shown in Table 5. Analyses of obtained water samples showed patterns dominated by $\alpha$ - and $\gamma$ $\mathrm{HCHs}$, whereas $\alpha-\mathrm{HCH}$ dominated the pattern of residual waste after the experiment. After $24 \mathrm{~h}$, the highest amount of transferred $\mathrm{HCH}$ was observed in the $\alpha$ - and $\gamma$-isomers, whereas only small amounts of $\beta-\mathrm{HCH}, \delta-\mathrm{HCH}$ and $\varepsilon-$ $\mathrm{HCH}$ were dissolved. Thereafter, all isomers exhibited decreased mobilization. Compared to the initial 4-h interaction with water, the following longer interaction periods removed less $\mathrm{HCH}$ from sample material. After 2 weeks, only $20-40 \%$ of initial amount of $\mathrm{HCHs}$ were dissolved. Net mobilizations were calculated as described before. Highest mobilization rates were determined for $\gamma$ $\mathrm{HCH}$ and $\delta$-HCH high (25 and $35 \%$, respectively). The other isomers exhibited much lower mobilization by a factor of 10 for $\varepsilon-\mathrm{HCH}$ and a factor of 100 for $\alpha-\mathrm{HCH}$ and $\beta-\mathrm{HCH}$. Therefore, it can be assumed that $\alpha-\mathrm{HCH}$ and $\gamma-\mathrm{HCH}$ mobilize initially to a greater extent than $\beta$ $\mathrm{HCH}, \delta-\mathrm{HCH}$ and $\varepsilon-\mathrm{HCH}$, although comparatively small amounts of $\delta-\mathrm{HCH}$ are readily transferred to the interacting water. Longer wastewater contact (during flood events) can be assumed to result in $\alpha-\mathrm{HCH}$-dominated wastewater/leaching water by depletion of the higher mobile $\gamma$ - and $\delta$-isomers.

\section{Soil samples and percolation}

The status of $\mathrm{HCH}$ contamination with increasing depth was assessed by analysis of a taken soil profile S3-S7. Five soil layers were separated according to changes in color and texture. The overall $\mathrm{HCH}$ concentration in the top layer S1 was very high reaching over $200 \mu \mathrm{g} / \mathrm{g}$ soil. A rapid decrease in $\mathrm{HCH}$ concentration was observed toward subjacent layers (S4-S7) with values down to $30 \mu \mathrm{g} / \mathrm{g}$ soil in the second layer (see Fig. 3a).

A HCH pattern (see Fig. 3b) very similar to the industrial waste $\mathrm{W} 1$ and sediment samples $\mathrm{S} 1$ and $\mathrm{S} 8$ was exhibited in the top layer S3. Here, $\alpha-\mathrm{HCH}$ predominated followed by $\beta-\mathrm{HCH}$. With increasing depth, a shift in the isomeric pattern of the $\mathrm{HCH}$ contamination occurred. In the second layer $\mathrm{S} 4$, the $\beta$-isomer became predominant followed by $\alpha-\mathrm{HCH}$ (see Fig. 3a). With increasing depth, the isomeric $\mathrm{HCH}$ pattern shifted toward $\beta-\mathrm{HCH}$ domination reaching more than $90 \%$ in the bottom layers and only small amounts of the other $\mathrm{HCH}$ isomers shown in Fig. 3b.

An isomeric discrimination by preferred transport of $\beta$ $\mathrm{HCH}$ into deeper soil layers is indicated by both this noticeable isomers shift and the exponential depletion of $\mathrm{HCH}$ concentration with increasing depth. Aside from transport processes simulated by desorption and percolation experiments, $\mathrm{HCH}$ isomers in soil are subject to discrimination by other processes. The initial alluvial deposit is subject to evaporation and photolysis as described previously. Furthermore, metabolization/biodegradation of $\mathrm{HCH}$ isomers by soil bacteria was observed by various authors (Bhatt et al. 2009). Aerobic biodegradations of HCHs in soil are well investigated for the bacteria Sphingomonadaceae (Pal et al. 2005). Degradation of HCHs is enabled by the exoenzymes LinA and LinB (Nagata et al. 1999; Suar et al. 2005; Raina et al. 2007; Bala et al. 2012; Geueke et al. 2013). Degradation thereby forms isomer-specific metabolization products such as pentachlorocyclohexene for $\alpha-\mathrm{HCH}$ and $\gamma$ $\mathrm{HCH}$ and pentachlorocyclohexane-1-ol for $\beta-\mathrm{HCH}$ and $\delta$ $\mathrm{HCH}$. Degradation of the most recalcitrant $\mathrm{HCH}$ isomer, the $\beta-\mathrm{HCH}$, is only achieved by $\operatorname{LinB}$, whereas LinA is able to degrade the other isomers. Therefore, a superimposition of the similar biodegradation pattern and percolation/mobilization pattern is suggested.

A second type of riverine particulate matter contaminated with HCHs in Bitterfeld-Wolfen area was represented by soils of riparian wetlands. This environmental 
Fig. 3 a Isomeric $\mathrm{HCH}$ distribution and concentration in a soil profile of a riparian wetland near Bitterfeld-Wolfen. Values are given in $\mu \mathrm{g} / \mathrm{g}$ d.w. b Comparison of isomeric $\mathrm{HCH}$ distributions in soil layers S3 (left) and S7 (right)

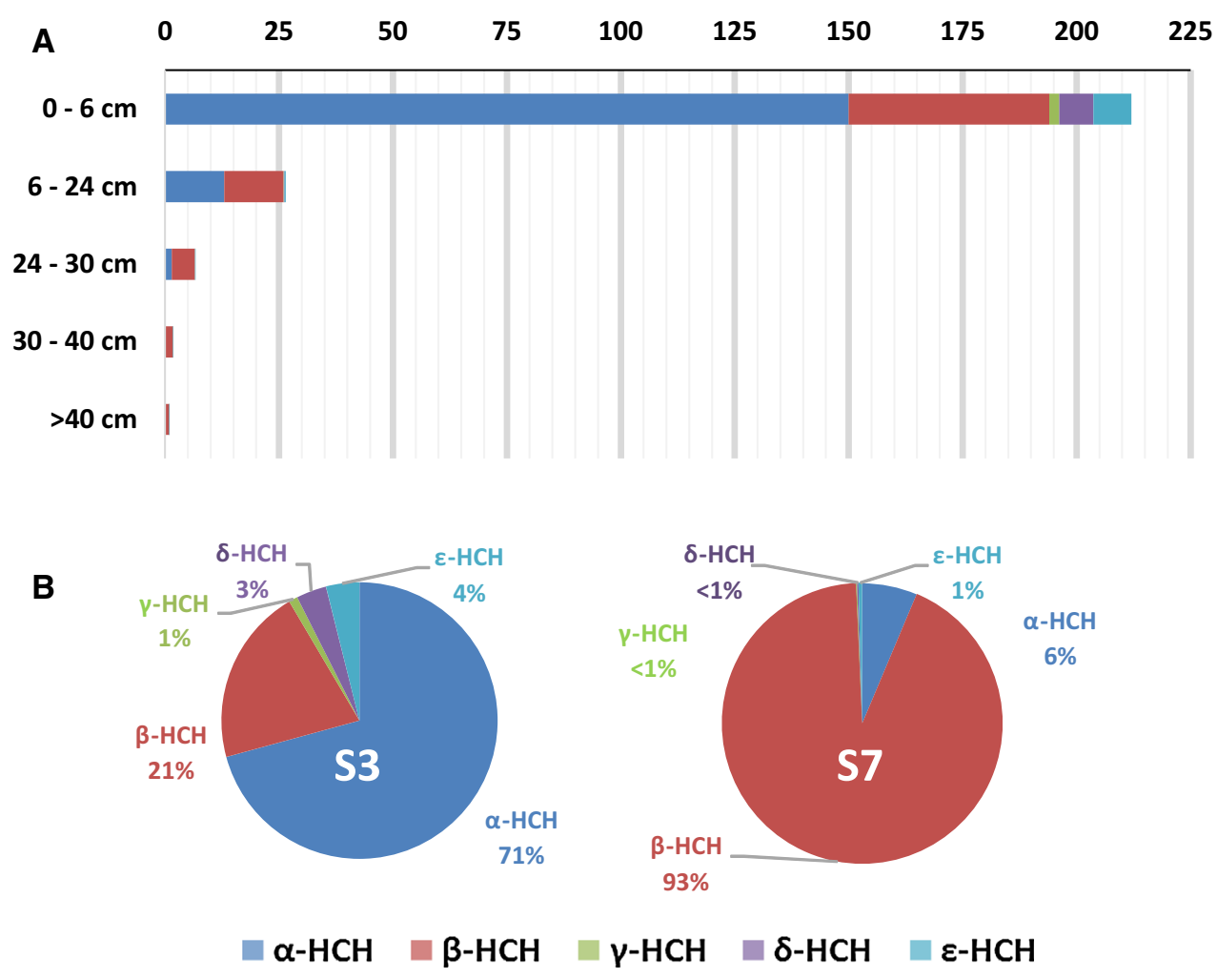

compartment is built up by deposition of contaminated sediments during flood events. In this particular system, wetlands and Spittelwasser creek are flooded frequently by the Mulde River. During rain events, wetland pollutants can be mobilized by percolating water through the unsaturated soil zone toward the groundwater.

The initial mobilization step was simulated by batch desorption experiments similar to sediment using sample $\mathrm{S} 2$ as representative (see Table 4). Significant mobilization of $\alpha-\mathrm{HCH}$ and even to a greater extent of $\beta-\mathrm{HCH}$ was already observed after $2 \mathrm{~h}$ of interaction. Mobilization of $\beta-\mathrm{HCH}, \delta-\mathrm{HCH}$ and $\varepsilon-\mathrm{HCH}$ increased slightly over the course of the experiment, while $\alpha-\mathrm{HCH}$ and $\gamma-\mathrm{HCH}$ remained constant. Mobilization was dominated by $\beta-\mathrm{HCH}$ and $\alpha-\mathrm{HCH}$ with a factor of 100 and 10 , respectively. Net mobilization values were calculated as described above. High mobilization rates were observed for $\beta-\mathrm{HCH}$ and $\varepsilon$ $\mathrm{HCH}$, low rates for $\alpha-\mathrm{HCH}, \gamma-\mathrm{HCH}$ and $\delta-\mathrm{HCH}$. In contrast to batch desorption experiments involving sediment samples, much lower dynamic behavior was observed in mobilization of $\mathrm{HCH}$ from soil samples. After $2 \mathrm{~h}$, the concentration of mobilized $\mathrm{HCH}$ already reached its maximum values. A distinct difference between mobilization in soil and mobilization in sediments is obvious. Therefore, water interacting with soil is likely to show a $\beta-\mathrm{HCH}-$ dominated $\mathrm{HCH}$ pattern. Further implication of this result will be discussed later.
For simulating the leaching of $\mathrm{HCH}$ contaminants into deeper soil layers, a percolation experiment with soil sample S2 was conducted. Over the course of the experiment, no significant change in the isomeric pattern of eluted water samples was observed (see Fig. 4a). Resulting patterns were strongly dominated by $\beta-\mathrm{HCH}(75-95 \%)$ followed by a minor percentage of $\alpha-\mathrm{HCH}(1-18 \%)$ and $\varepsilon$ $\mathrm{HCH}$ (1-4\%). Other isomers were eluted to a lesser amount $(<1 \%)$. Results from the percolation experiment on soil indicate a preferred desorption of $\beta-\mathrm{HCH}$ and subsequent transport to deeper soil layers by water. This observation supports not only experimental data from batch desorption experiments (higher mobilization of $\beta-\mathrm{HCH}$ in soil) but also the analyses of $\mathrm{HCH}$ content in soil layers $(\beta$ isomer-dominated $\mathrm{HCH}$ patterns in deeper soil layers). The other $\mathrm{HCH}$ isomers were in contrast much less mobile and will therefore stay more adsorbed to particulate soil matter. Depletion of $\beta$-HCH in upper soil layers and a shift in the $\mathrm{HCH}$ pattern toward remaining isomers is implied.

After flood events, deposited contaminated sediments on riparian wetlands are also subject to rinsing out, e.g., by rainfall. These events were simulated by percolation experiment with sediment sample S8 (see Fig. 4b). Over the course of this experiment, $\mathrm{HCH}$ patterns of eluted water samples showed an increase in $\varepsilon-\mathrm{HCH}$ content (49-82 \%), an almost constant leaching of $\delta-\mathrm{HCH}(\sim 4 \%)$, a slight decrease in $\beta-\mathrm{HCH}(15-7 \%)$ and a stronger decrease in $\alpha$ - 
Fig. 4 Isomeric $\mathrm{HCH}$ distribution in eluted water samples of a percolation experiment using a soil sample S2, b sediment sample S8 and c waste sample W1. Each pattern represents a step of $100 \mathrm{~mL}$ eluted water for a total of $1 \mathrm{~L}$

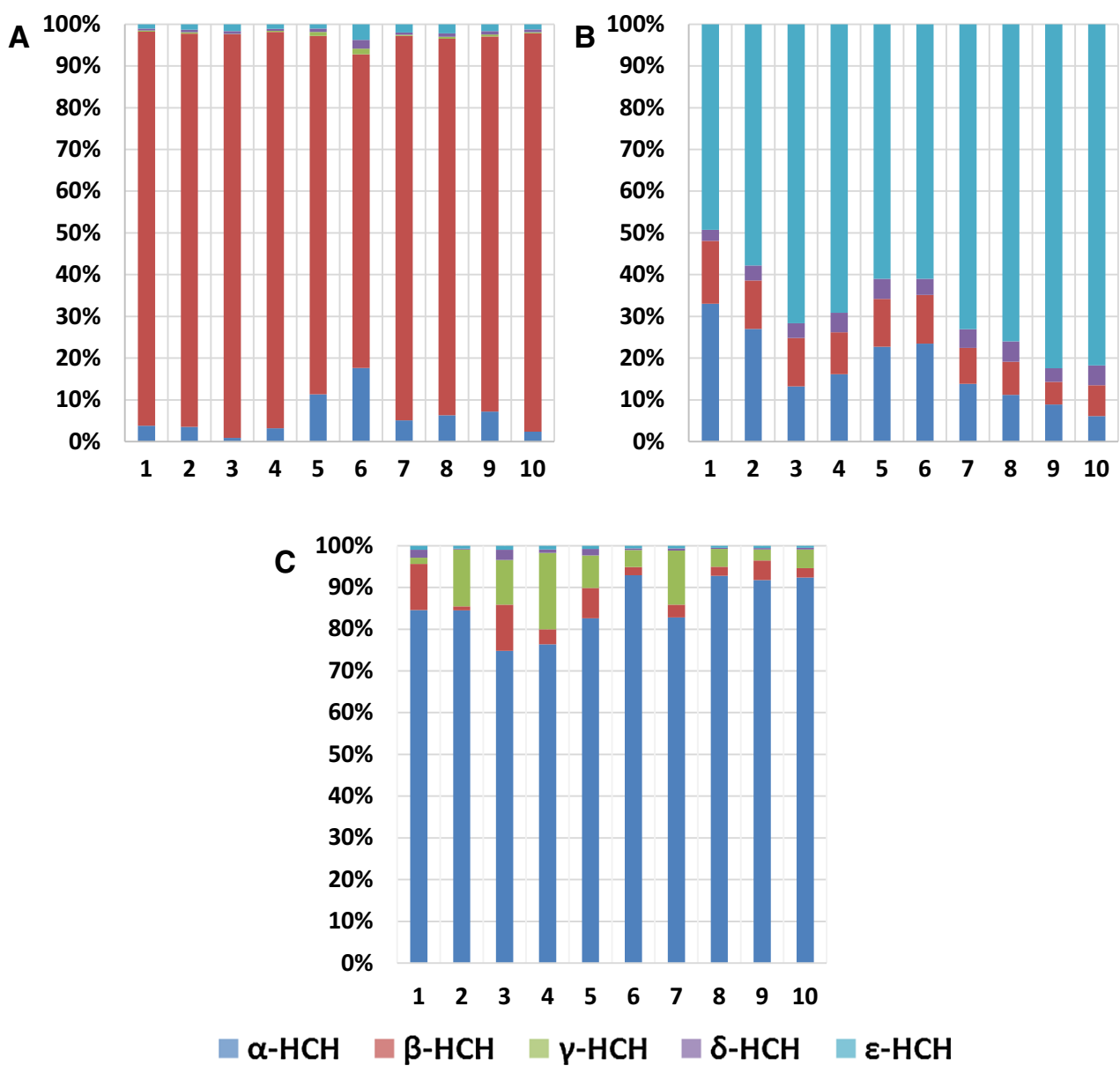

$\mathrm{HCH}(33-6 \%)$. The $\gamma$-isomer was not detected in any of the eluates. Preferred desorption of $\varepsilon-\mathrm{HCH}$ increasing over time is suggested by the results from percolation experiment using sediment. A subsequent transport of $\varepsilon-\mathrm{HCH}$ in subjacent soil can be assumed. Initial mobilization of $\alpha$ and $\beta$-HCHs decreased over time. These observations were different to the results obtained from percolation experiment applied to the soil sample.

Combined results point to an increased transport of $\varepsilon$ $\mathrm{HCH}$ from accumulated polluted sediments into subjacent riparian wetland soil after a flood event. Thereafter, further transfer of $\varepsilon-\mathrm{HCH}$ and $\beta-\mathrm{HCH}$ into groundwater may occur as indicated by elevated mobilization rates.

For simulating the leaching of $\mathrm{HCH}$ contaminants directly from buried industrial waste of $\mathrm{HCH}$ residues, a percolation experiment with waste sample W1 was conducted. Over the course of the experiment, no significant change in the isomeric pattern in eluted water samples was observed (see Fig. 4c). Resulting patterns were strongly dominated by $\alpha$ $\mathrm{HCH}(75-93 \%)$ followed by a minor percentage of $\gamma-\mathrm{HCH}$ (1-18\%) and $\beta$-HCH (1-11\%). Other isomers were eluted to a lesser amount $(\sim 1 \%)$. Results from the percolation experiment on this matured $\mathrm{HCH}$ waste indicate a preferred desorption of $\alpha-\mathrm{HCH}$ and subsequent transport to subjacent soil layers. In contrast to batch desorption experiments with waste sample $\mathrm{W} 1, \gamma-\mathrm{HCH}$ was eluted to a lesser extent. It can be assumed that much shorter interactions with water during elution in percolation experiments compared to batch desorption experiments impede equilibrium of $\mathrm{HCH}$ in water/ waste and therefore discriminate desorption and solubility of $\gamma-\mathrm{HCH}$.

In comparison with water sample L1, batch desorption experiments with waste sample W1 showed elevated amounts of $\gamma-\mathrm{HCH}$ transferred to the water phase. Patterns of leaching water from corresponding percolation experiment (see Fig. 4c) showed a similar $\alpha$-HCH domination relative to water sample L1. However, amounts of the $\beta$ and $\gamma$-isomers did not match. Therefore, the water sample L1 does not represent direct leaching water from this composition of industrial $\mathrm{HCH}$ waste.

\section{Comparison of $\mathrm{HCH}$ behavior in sediment, soil and waste}

The conducted laboratory experiments revealed main differences in amount and distribution of $\mathrm{HCH}$ isomers as 
Fig. 5 Comparison of the outcome of batch desorption and percolation experiments using different samples types: soil S2 (left), sediment S8 (middle) and $\mathrm{HCH}$ waste $\mathrm{W} 1$ (right)

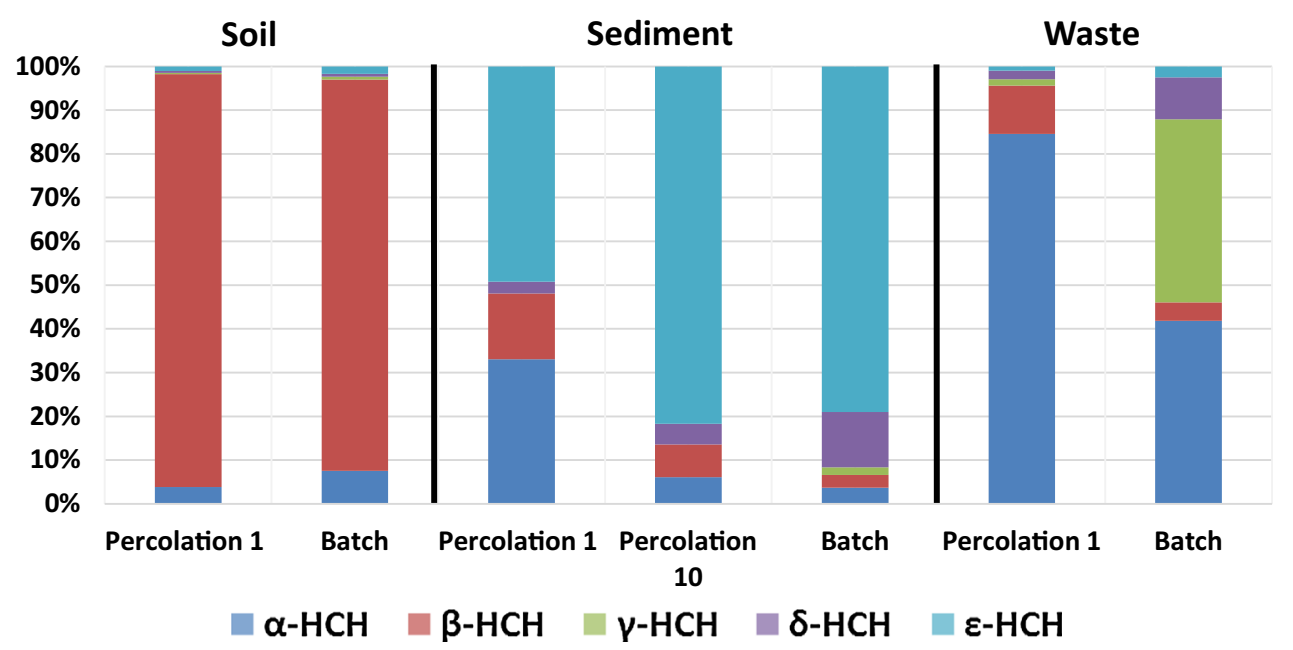

well as temporal changes in mobilization rates between subaquatic sediment and terrestrial soil. This is astonishing since both environmental compartments originate from the same riverine particulate matter (see Fig. 5). On the one hand, experiments with the soil sample resulted in $\beta-\mathrm{HCH}-$ dominated patterns and no change in composition of eluted $\mathrm{HCH}$ patterns over the time course of the percolation experiment and fast increasing mobilization rates with time toward constant values. On the other hand, experiments with the sediment sample showed $\varepsilon-\mathrm{HCH}$-dominated patterns with an increasing contribution of $\varepsilon-\mathrm{HCH}$ in the eluted $\mathrm{HCH}$ pattern and slow increasing mobilization rates with time toward constant values. A third experimental behavior was observed in the industrial $\mathrm{HCH}$ waste. Over the time course of the $\mathrm{HCH}$ waste percolation experiment, $\alpha$-isomer-dominated $\mathrm{HCH}$ patterns were eluted with no change in isomeric distribution, whereas slow decreasing mobilization rates with time toward constant values were observed.

In summary, experimental setups with three types of sample material resulted in different $\mathrm{HCH}$ patterns as well as a different mobilization rate. Obviously, the observed differences are related to the type of sample and the corresponding interaction with the $\mathrm{HCH}$ contamination. Aging, describing changes in properties of environmental contaminants over time due to different environmental conditions (e.g., level of oxygen, $\mathrm{pH}$ value, exposure to light, type and quantity of microbacteria) strongly influences association and mobilization of HCHs. Prolonged aging under terrestrial conditions (e.g., with elevated levels of oxygen and higher exposure to light) results in a weaker association of $\mathrm{HCH}$ with particulate matter indicated by a faster mobilization toward a steady state than aging under subaquatic conditions. Despite differences in content and quality of TOC and particle size (Table 2, Table S2), no correlation was illustrated with $\Sigma-\mathrm{HCH}$ or selected isomers.

\section{Conclusion}

Results from desorption experiments support the observation in the natural system. In the Schachtgraben canal, a strong depletion of $\alpha$ - and $\beta$-HCHs was observed, whereas these isomers exhibit the weakest mobilization in the batch desorption experiments; thus, a strong adsorption to particulate matter can be assumed. Furthermore, as concentrations of $\mathrm{HCH}$ in water are much lower than in sediment, small changes in particulate matter composition (SOM, clay minerals, hydroxides) and amount have huge impact on the $\mathrm{HCH}$ isomer distribution in the corresponding water phase. Both analyses of the natural system and the batch desorption experiments revealed water-suspended matter interaction to be a dominant factor in composition of the isomeric pattern whereby adsorption of $\alpha$ - and $\beta$-HCHs is preferred over $\mathrm{y}-, \delta$ - and $\varepsilon$-HCHs.

In soils, a depth-dependent decrease in concentration and a shift from $\alpha$ - to $\beta-\mathrm{HCH}$ predomination were observed. Laboratory experiments support the assumption of an isomeric discrimination by preferred desorption of $\beta$ $\mathrm{HCH}$ and subsequent leaching in subjacent soil layers resulting in a weaker adsorption of $\beta-\mathrm{HCH}$ to terrestrial particulate matter.

Environmental conditions seem to be responsible for the different behaviors of $\mathrm{HCH}$ contaminations in different environmental matrices. Variations in aging conditions (subaquatic, terrestrial) change the strength of association of $\mathrm{HCH}$ with particulate matter. This result not only in different mobilization rates in total but also in preferential mobilization of individual isomers depending on the type of matrix. 
Acknowledgments Financial support for this study was provided by the German Federal Ministry of Transport and Digital Infrastructure (BMVI) within the scope of the I-HEX project. We want to thank Mrs. Schaffranka and Mr. Zauter from the Landesanstalt für Altlastenfreistellung of Saxony-Anhalt for guidance during our sampling and for provision of the matured industrial $\mathrm{HCH}$ waste.

\section{References}

Abhilash PC, Jamila S, Singh V, Singh A, Singh N, Srivastava SC (2008) Occurrence and distribution of hexachlorocyclohexane isomers in vegetation samples from a contaminated area. Chemosphere 72:79-86

Ali U, Syed JH, Malik RN, Katsoyiannis A, Li J, Zhang G, Jones KC (2014) Organochlorine pesticides (OCPs) in South Asian region: a review. Sci Total Environ 476:705-717

Bachmann A, Walet P, Wijnen P, Debruin W, Huntjens JLM, Roelofsen W, Zehnder AJB (1988) Biodegradation of alphahexachlorocyclohexane and beta-hexachlorocyclohexane in a soil slurry under different redox conditions. Appl Environ Microb 54:143-149

Bala K et al (2012) Enzymatic conversion of epsilon-hexachlorocyclohexane and a heptachlorocyclohexane isomer, two neglected components of technical hexachlorocyclohexane. Environ Sci Technol 46:4051-4058

Bhatt P, Kumar MS, Chakrabarti T (2009) Fate and degradation of POP-hexachlorocyclohexane. Crit Rev Environ Sci Technol 39:655-695

Deo PG, Hasan SB, Majumder SK (1980) Isomerization of beta-HCH in aqueous solution. J Environ Sci Health B 15:147-164

Ding X et al (2007) Atmospheric hexachlorocyclohexanes in the North Pacific Ocean and the adjacent Arctic region: spatial patterns, chiral signatures, and sea-air exchanges. Environ Sci Technol 41:5204-5209

Dsikowitzky L, Schwarzbauer J, Littke R (2002) Distribution of polycyclic musks in water and particulate matter of the Lippe River (Germany). Org Geochem 33:1747-1758

Franke S, Hildebrandt S, Schwarzbauer J, Link M, Francke W (1995) Organic-compounds as contaminants of the Elbe river and its tributaries. 2. Gc/Ms screening for contaminants of the Elbe water. Fresenius J Anal Chem 353:39-49

Franke S, Heinzel N, Specht M, Francke W (2005) Identification of organic pollutants in waters and sediments from the Lower Mulde river area. Acta Hydrochim Hydrobiol 33:519-542

Gandrass J, Zoll M (1996) Chlorinated hydrocarbons in sediments of the elbe catchment area-analytical methods and status of pollution. Acta Hydrochim Hydrobiol 24:212-217

Geueke B, Miska ME, Poiger T, Rentsch D, Lal R, Holliger C, Kohler HPE (2013) Enantioselective dehydrochlorination of deltahexachlorocyclohexane and delta-pentachlorocyclohexene by LinA1 and LinA2 from Sphingobium indicum B90A. Appl Environ Microb 79:6180-6183

Heemken OP, Stachel B, Theobald N, Wenclawiak BW (2000) Temporal variability of organic micropollutants in suspended particulate matter of the River Elbe at Hamburg and the River Mulde at Dessau, Germany. Arch Environ Contam Toxicol 38:11-31

Heim S, Ricking M, Schwarzbauer J, Littke R (2005) Halogenated compounds in a dated sediment core of the Teltow canal, Berlin: time related sediment contamination. Chemosphere 61:1427-1438

Heinisch E, Kettrup A, Bergheim W, Martens D, Wenzel S (2005) Persistent chlorinated hydrocarbons (PCHC), source oriented monitoring in aquatic media 3. The isomers of hexachlorocyclohexane. Fresenius Environ Bull 14:444-462

Huhnerfuss H, Faller J, Konig WA, Ludwig P (1992) Gas-chromatographic separation of the enantiomers of marine pollutants. 4 . Fate of hexachlorocyclohexane isomers in the Baltic and NorthSea. Environ Sci Technol 26:2127-2133

Huhnerfuss H, Bester K, Landgraff O, Pohlmann T, Selke K (1997) Annual balances of hexachlorocyclohexanes, polychlorinated biphenyls and triazines in the German Bight. Mar Pollut Bull 34:419-426

Iwata H, Tanabe S, Ueda K, Tatsukawa R (1995) Persistent organochlorine residues in air, water, sediments, and soils from the Lake Baikal Region, Russia. Environ Sci Technol 29:792-801

Jacobs P, Krautter N, Diesner K (2013) Frachtreduzierung SpittelwasserAbschlussbericht. http://www.laf-lsa.de/fileadmin/Bibliothek/ Politik_und_Verwaltung/MLU/LAF/WRRL/Fachbericht_Fracht reduzierung_Spittelwasser.pdf. Accessed 29.01. 2015

Karlsson $\mathrm{H}$ et al (2000) Persistent chlorinated pesticides in air, water, and precipitation from the Lake Malawi area, southern Africa. Environ Sci Technol 34:4490-4495

Kolarikova K, von Tumpling W, Bartels P (2013) Bioaccumulation of $\mathrm{HCH}$ isomers in selected macroinvertebrates from the Elbe River: sources and environmental implications. Environ Monit Assess 185:4333-4346

Kumar A, Dayal P, Shukla G, Singh G, Joseph PE (2006) DDT and $\mathrm{HCH}$ residue load in mother's breast milk: a survey of lactating mother's from remote villages in Agra region. Environ Int 32:248-251

Li HS, Ling WF, Lin CX (2011a) Fishpond sediment-borne DDTs and $\mathrm{HCH}$ in the Pearl River Delta: characteristics, environmental risk and fate following the use of the sediment as plant growth media. J Hazard Mater 186:1474-1480

Li SL, Elliott DW, Spear ST, Ma LM, Zhang WX (2011b) Hexachlorocyclohexanes in the environment: mechanisms of dechlorination. Crit Rev Environ Sci Technol 41:1747-1792

Macrae IC, Raghu K, Castro TF (1967) Persistence and biodegradation of four common isomers of benzene hexachloride in submerged soils. J Agric Food Chem 15:911-914

Malaiyandi M, Muzika K, Benoit FM (1982) Isomerization of $\gamma$ hexachlorocyclohexane to its $\alpha$-isomer by UV-light irradiation. J Environ Sci Health A 17:299-311

Manz M, Wenzel KD, Dietze U, Schuurmann G (2001) Persistent organic pollutants in agricultural soils of central Germany. Sci Total Environ 277:187-198

Marth P, Oxynos K, Schmitzer J, Schramm KW, Kettrup A (1997) Levels of chlorinated hydrocarbons $(\mathrm{CHC} 1)$ in breams (Abramis brama) from the river elbe (a contribution to the federal Environmental Specimen Bank). Chemosphere 34:2183-2192

Nagata Y, Miyauchi K, Takagi M (1999) Complete analysis of genes and enzymes for $\gamma$-hexachlorocyclohexane degradation in Sphingomonas paucimobilis UT26. J Ind Microbiol Biotechnol 23:380-390

Oliveira EC, Paumgartten FJR (1997) Comparative study on the acute toxicities of $\alpha, \beta, \gamma$, and $\delta$ isomers of hexachlorocyclohexane to freshwater fishes. Bull Environ Contam Toxicol 59:984-988

Olivero-Verbel J, Guerrero-Castilla A, Ramos NR (2011) Biochemical effects induced by the hexachlorocyclohexanes. Rev Environ Contam Toxicol 212:1-28

Pal R et al (2005) Hexachlorocyclohexane-degrading bacterial strains Sphingomonas paucimobilis B90A, UT26 and Sp+, having similar lin genes, represent three distinct species, Sphingobium indicum sp nov., Sphingobium japonicum sp nov and Sphingobium francense sp nov., and reclassification of [Sphingomonas] 
chungbukensis as Sphingobium chungbukense comb. nov. Int J Syst Evol Microbiol 55:1965-1972

Phillips TM, Seech AG, Lee H, Trevors JT (2005) Biodegradation of hexachlorocyclohexane $(\mathrm{HCH})$ by microorganisms. Biodegradation 16:363-392

Raina V et al (2007) Hydroxylated metabolites of $\beta$ - and $\delta$ hexachlorocyclohexane: bacterial formation, stereochemical configuration, and occurrence in groundwater at a former production site. Environ Sci Technol 41:4292-4298

Ricking M, Schwarzbauer J (2008) HCH residues in point-source contaminated samples of the Teltow Canal in Berlin, Germany. Environ Chem Lett 6:83-89

Rodriguez-Garrido B, Arbestain MC, Monterroso MC, Macias F (2004) Reductive dechlorination of $\alpha$-, $\beta$-, $\delta$-, and $\gamma$-hexachlorocyclohexane isomers by hydrocobalamin in the presence of either dithiothreitol or titanium(III) citrate as reducing agents. Environ Sci Technol 38:5046-5052

Schmidt C et al (2008) Contaminant mass flow rates between groundwater, streambed sediments and surface water at the regionally contaminated site Bitterfeld. Grundwasser 13:133-146

Schwartz R, Gerth J, Neumann-Hensel H, Bley S, Forstner U (2006) Assessment of highly polluted fluvisol in the Spittelwasser floodplain-based on national guideline values and MNAcriteria. J Soil Sediment 6:145-155

Sharma BM, Bharat GK, Tayal S, Nizzetto L, Cupr P, Larssen T (2014) Environment and human exposure to persistent organic pollutants (POPs) in India: a systematic review of recent and historical data. Environ Int 66:48-64

Stockholm Convention on POPs. Decision SC-4/10, SC-4/11 and SC4/15, Stockholm convention. Reports and decisions. http://chm. pops.int/Convention/ConferenceofthePartiesCOP/COPDecisions/ tabid/208/Default.aspx. Accessed 19.01.2015
Suar M et al (2005) Enantioselective transformation of $\alpha$-hexachlorocyclohexane by the dehydrochlorinases LinA1 and LinA2 from the soil bacterium Sphingomonas paucimobilis B90A. Appl Environ Microbiol 71:8514-8518

Venier M, Hites RA (2014) DDT and HCH, two discontinued organochlorine insecticides in the Great Lakes region: isomer trends and sources. Environ Int 69:159-165

Walker K, Vallero DA, Lewis RG (1999) Factors influencing the distribution of lindane and other hexachlorocyclohexanes in the environment. Environ Sci Technol 33:4373-4378

Wania F, Mackay D (1996) Tracking the distribution of persistent organic pollutants. Environ Sci Technol 30:A390-A396

Wilken M, Walkow F, Jager E, Zeschmarlahl B (1994) Flooding area and sediment contamination of the river Mulde (Germany) with $\mathrm{PCDD} / \mathrm{F}$ and other organic pollutants. Chemosphere 29:2237-2252

Willett KL, Ulrich EM, Hites RA (1998) Differential toxicity and environmental fates of hexachlorocyclohexane isomers. Environ Sci Technol 32:2197-2207

Wu WZ, Xu Y, Schramm KW, Kettrup A (1997) Study of sorption, biodegradation and isomerization of $\mathrm{HCH}$ in stimulated sediment/water system. Chemosphere 35:1887-1894

Xiao H, Li NQ, Wania F (2004) Compilation, evaluation, and selection of physical-chemical property data for $\alpha-, \beta-$, and $\gamma$ hexachlorocyclohexane. J Chem Eng Data 49:173-185

Zou E, Matsumura F (2003) Long-term exposure to $\beta$-hexachlorocyclohexane $(\beta-\mathrm{HCH})$ promotes transformation and invasiveness of MCF-7 human breast cancer cells. Biochem Pharmacol $66: 831-840$ 